\title{
Future Trends in Synthetic Biology: What to Expect in Asia
}

\author{
Ning Mao ${ }^{1}$, Chueh Loo Poh ${ }^{1}$, Wen Shan Yew ${ }^{1}$, and Matthew Chang ${ }^{1}$ \\ ${ }^{1}$ Singapore Consortium for Synthetic Biology
}

October 1, 2020

\begin{abstract}
Synthetic biology research and technology translation has garnered increasing interest from the governments and private investors in Asia, where the technology has great potential in driving a sustainable bio-based economy. This Perspective reviews the latest developments and future directions in synthetic biology research and applications, with highlights of important developments from Asia. It also suggests plans for more effective multi-lateral collaborations that promote a sustainable development of the field and mitigate potential biosecurity risks. Through these discussions, stakeholders from different groups, including academia, industry and government, are expectantly better positioned to contribute towards the establishment of innovation and bio-economy hubs in Asia.
\end{abstract}

\section{Hosted file}

Manuscript.pdf available at https://authorea.com/users/363636/articles/484345-future-trendsin-synthetic-biology-what-to-expect-in-asia 